\title{
Paisagens no Turismo: entre os paradigmas do olhar e da performance
}

\author{
Touristscapes: between gazing and performance paradigms
}

Paisajes del turismo: entre los paradigmas de la mirada y de la performance

\author{
Jaciel Gustavo Kunz ${ }^{1}$ \\ https://orcid.org/0000-0002-0578-2457 \\ Antonio Carlos Castrogiovanni $^{2}$ \\ https://orcid.org/0000-0002-2146-9700 \\ Maurício Ragagnin Pimentel ${ }^{3}$ \\ https://orcid.org/0000-0003-1071-8385
}

\begin{abstract}
RESUMO: Primeiramente, objetiva-se reapresentar o caráter central da visibilidade, contida na percepção e no estudo das paisagens em geral, e das turísticas, em particular. Secundariamente, objetiva-se contrapor distintos paradigmas, o do olhar e o da performance, para demonstrar a relativa migração do primeiro para o segundo, em estudos da paisagem no/pelo Turismo. Para tal, recorre-se a uma revisão da literatura, especialmente Anglo-saxã, atinente ao Turismo e à Geografia HumanistaCultural. Busca-se redimensionar o conhecimento referente a essas questões, pelo menos no modo como a problemática vem sendo encaminhada pela Geografia e pelo Turismo no Brasil. Baseando-se no paradigma do olhar turístico (gazing), considera-se que o sentido da visão não está dissociado dos demais, e não está afastado das práticas corporificadas (performing). Questiona-se até que ponto os dois paradigmas (gazing e performing) são de fato antagônicos, ou se dialogicamente se complementam no estudo das paisagens no Turismo. Ainda, cogita-se que as performances turísticas sejam o elo entre o olhar e as práticas, abordagens por vezes alijadas. Por fim, preconiza-se que metodologias apoiadas no uso da fotografia podem ser um modo privilegiado de estudar visualmente as paisagens, e também os aspectos performáticos do turismo.
\end{abstract}

PALAVRAS-CHAVE: Paisagens. Turismo. Olhar. Performance. Fotografia.

ABSTRACT: This essay aims to re-present the central role occupied by visuality in studying and experiencing landscapes in general, and, particularly, touristscapes. The distinct gazing and performing research paradigms are contrasted to demonstrate a relative theoretical, conceptual framework shift from the first to the latter in tourist landscape research. For the purpose of this

\footnotetext{
${ }^{1}$ Doutorando em Geografia (UFRGS) e Professor na FURG. E-mail: jacielkunz@gmail.com.

2 Doutor em Comunicação Social (PUC-RS). Professor na PUC-RS e na UFRGS. E-mail: castroge@ig.com.br.

${ }^{3}$ Doutor em Geografia (UFRGS). Professor na UFPel. E-mail: mauricioragagnin@gmail.com.
} 
demonstration, literature pertaining to Tourism and Cultural-Humanistic Geography, especially from Anglo-Saxon authors, is reviewed. The purpose is to restructure the knowledge correspondent to these subjects, at least the way they have been approached by Geography and Tourism in Brazil. Grounded on the gazing paradigm, we consider that the sense of sight is not detached from the others, and that it is not distant from the embodied practices (performing). The question is to what extent the two paradigms (gazing and performing) are in fact antagonic, or whether they complement each other dialogically in the study of landscapes in Tourism. In addition, we consider that tourist performances are the link between the gaze and the practices, approaches that are sometimes dismissed. Finally, we propose that methodologies grounded on the use of photography can be a privileged way to visually study the landscapes, as well as the performative aspects of tourism.

KEYWORDS: Landscape. Tourism. Gazing. Performance. Photography.

RESUMEN: Este ensayo teórico pretende replantear el carácter central de la visibilidad, presente en la percepción y el estudio de los paisajes en general, y de los turísticos en particular. En segundo lugar, pretende contrastar diferentes paradigmas, el de la mirada y el de la performance, para demostrar la relativa migración teórica y conceptual del primero al segundo en los estudios del paisaje en/por el Turismo. Para ello, recurrimos a una revisión bibliográfica, especialmente anglosajona, relacionada tanto con el Turismo como con la Geografía Humanista-Cultural. El propósito es redimensionar el conocimiento sobre estas cuestiones, al menos en la forma en que el problema se ha tratado por la Geografía y el Turismo en Brasil. A partir del paradigma de la mirada, se considera que el sentido de la vista no está disociado de los demás, y no está alejado de las prácticas corporales (performing). Se cuestiona hasta qué punto los dos paradigmas (mirada y performance) son de hecho antagónicos, o si se complementan dialógicamente en el estudio de los paisajes en el Turismo. Además, se sostiene que las actuaciones turísticas son el nexo de unión entre la mirada y las prácticas, planteamientos que a veces se desestiman. Finalmente, se defiende que las metodologías apoyadas en el uso de la fotografía pueden ser una forma privilegiada de estudiar visualmente los paisajes, así como los aspectos performativos del turismo.

PALABRAS CLAVE: Paisajes. Turismo. Mirada. Performance. Fotografía.

\section{INTRODUÇÃO}

Embora a paisagem seja considerada um dos conceitos fundamentais da pesquisa socioespacial, notadamente, da Geografia (SOUZA, 2016), suaconsiderável abrangência exige o estudo e a aplicação em muitas áreas, incluindo o Turismo (a palavra grafada em maiúscula sugere o campo de estudos consolidado. As palavras em minúsculas, ao longo do texto, dizem respeito ao fenômeno sociocultural complexo, à atividade econômica ou à cadeia produtiva).

Para Terkenli (2007) a chamada "paisagem turística" exige interpretação contextual, levando-se em contaa posição de um(a)observador(a), na medida em que o próprio turismo seria definido por encontros (CROUCH, 1999; TERKENLI, 2007) entre sujeitos/turistas e espaço, sujeitos/turistas e paisagem, e assim por diante. É importante, assim, lançar luz aos modos pelos quais a paisagem participa das experiências turísticas (TERKENLI, 2007). A experiência das paisagens turísticas é uma das três tendências de pesquisa das Geografias (Culturais) do Turismo, em paralelo à da construção de sítios turísticos, e a das 
representações do turismo: todas são igualmente importantes, além de complementares (KNUDSEN; RICKLY-BOYD; METRO-ROLAND, 2012).

Alega-se que a interface entre Turismo e Geografia, ao tratar turismo/lazer como fenômenos socioespaciais, se estabelece tanto pelas alterações objetivas/materiais que incitam, quanto pela mediação simbólica da relação entre sujeitos e espaço; orientando, assim, uma estética a ser apreciada e consumida nas/pelas paisagens do turismo/lazer, de modo indissociável a suas práticas ( $\mathrm{CROUCH}, 1999)$.

Em termos do "olhar do turista", "Vistas frequentemente requerem paisagens sonoras e olfativas apropriadas para que sejam objetos acalentados do olhar do turista" (LARSEN; URRY, 2011, p. 1115, tradução nossa). Há que se associar de imediato a relação desse termo à obra de Urry (1996), traduzida e publicada no Brasil, a mais referenciada deste autor no país.

Nesse sentido, quando alguém viaja, a paisagem é oque se coloca entre um sujeito e um Outro (sujeito ou local), servindo ainda como mediadora da experiência do turista com esse Outro. A alteridade, perseguida pelos turistas em suas viagens, não se refere apenas a sujeitos, mas também a paisagens (MACCANNELL, 2011). O que se olha como turistas - as paisagens são fundamentais - pode ter sido organizado ou arranjado previamente: os turistas se deslocam para determinados locais exatamente porque outros turistas visitaram essas paisagens antes (MACCANNELL, 2001).

O olhar turístico é construído por meio de signos, uma vez que o turismo envolve em si uma coleção de signos; esse olhar (gazing) conecta signos aos objetos referentes (LARSEN; URRY, 2011), ou entre atrações e seus marcadores, nos termos de MacCannell (1999). As paisagens turísticas, como paisagens culturais, reforçam os elos entre Turismo e atividade semiótica. A Semiótica é a ciência devotada aos signos, de todo tipo.

Sendo assim, paisagens culturais são textos altamente reflexivos e multifacetados, construídos camada sobre camada ao longo do tempo. A perspectiva ou a teoria do texto é uma das muitas possibilidades da Semiótica e/ou dos Estudos da Linguagem. As paisagens turístico-culturais vêm sendo alteradas pouco a pouco, por todo sujeito que por ela passa. Assim, a paisagem vista culturalmente, como a turística, é uma coleção de símbolos a decifrar: um verdadeiro exercício de semiótica (KNUDSEN; RICKLY-BOYD; METROROLAND, 2012).

Em uma dimensão sócio-histórica, há, de acordo com os distintos "modos de ver", distintas histórias e geografias da visão (CAUQUELIN, 2007), que inauguram nos anos 1980 e 1990, então novas conceituações e perspectivas no estudo das paisagens pela Nova Geografia Cultural em que o geógrafo Denis Cosgrove é um dos principais expoentes (WYLIE, 2007). Esses "modos de ver" podem variar enormemente de acordo com o indivíduo, o gênero, a cultura etc .Isto posto, Cauquelin (2007, p. 11), define paisagem como 
"[...] conjunto de valores ordenados em uma visão" (grifo da autora). Diante disso, "uma "bela paisagem' satisfaz, para nós, condições que são comuns à nossa cultura" (CAUQUELIN, 2007, p. 114).

Assim, nota-se desde a Geografia Clássica uma longa tradição em termos da conexão entre paisagem e visão. Conexão esta que continua forte e poderosa. E, exatamente pelos entrelaçamentos com o fenômeno da visão, a paisagem extravasa a estreita definição disciplinar da/pela Geografia (COSGROVE, 2008).

A paisagem, como experiência num mundo vivido, é tida sempre como uma sequência de imagens, derivadas da mudança de espaços em transformação, em termos de perspectiva ou ponto de vista, mas também de luz, presença/ausência, narrativas... (MINCA, 2008). Nesse empreendimento, é-se sujeito que não tem plena consciência do uso de determinados artifícios para percepção, contemplação, admiração e desfrute e interpretação de paisagens (turísticas): "[...] acreditamos estar simplesmente fazendo uso de nossos sentidos", diz Cauquelin (2007, p. 114). Houve contínua evolução da experiência e da concepção espaciais, concomitantes ao desenvolvimento de técnicas e significados do ver no Ocidente moderno (COSGROVE, 2002, 2008). E, se os conteúdos mudaram a experiência do mundo também (CAUQUELIN, 2007). Isso ocorre à medida que a tecnologia evidencia a artificialidade na constituição da paisagem.

Antes isso, a técnica da perspectiva linear na pintura é incorporada como artifício e avanço geométrico para a representação visual do espaço e das paisagens (GASTAL, 2013), uma metáfora da Modernidade, nos diz Panofsky (2017). A perspectiva inclusive pautou a concepção de O Olhar do Turista de Urry (1996). MacCannell (2001) considera que o sujeito do olhar do turista é aquele ocidental, remanescente da perspectiva do Renascimento: um sujeito que se concebe como fonte e centro de tudo, mas que falha ao não reconhecer tal condição, isto é, um sujeito que se outorga certa superioridade e primazia no/do seu olhar.

Associa-se decisivamente a experiência turística à perspectiva linear, de modo a considerá-la estratégia clara de posicionamento e de observação. Na transformação da paisagem em mercadoria pelo turismo, distintas abordagens teóricas se confundem, o que dificulta o entendimento do significado de paisagem turística. A adoção da paisagem pela atividade turística, e pela experiência turística, como objeto e, ao mesmo tempo, como perspectiva, um "modo de ver", experimentou considerável maleabilidade. Isso porque o uso ambivalente do conceito de paisagem pela cadeia produtiva do turismo contribui para confundir o objeto com seu processo de produção, ao conceber simultaneamente a paisagem como espaço inabitado e como uma perspectiva (MINCA, 2007). 
Diversos autores, entre eles Cosgrove (2002), Minca (2007) e Tuan (2012), apontam uma primazia da visão na experimentação do espaço, em termos estéticos, mas também de percepção e representação do mundo. Tal hegemonia tornou-se evidente numa variedade de formas, modos e expressões, no mundo Moderno (MINCA, 2007).

A pintura é uma das formas mais expressivas do sentido da visão que já houve (CAUQUELIN, 2007). Mencione-se a pintura de paisagem, que figura como gênero pictórico específico (GOMES, 2013), com apogeu durante o Romantismo. Quanto a esse gênero de pintura, é necessário mencionar que foram os "Poemas, meditações, relatos de viagem abriram o caminho. A pintura vai ao encalço [...]" (CAUQUELIN, 2007, p. 93). Além disso, as relações entre literatura e pintura de paisagens vão além: "O texto [literário] acompanha, redobrando seu efeito, a própria realização" (CAUQUELIN, 2007, p. 93). Surge, assim, maior interesse pela visualização direta e imediata das paisagens descritas por palavras, na medida em que "[...] as palavras podem mentir; a imagem, por seu lado, parece fixar o que existe" (CAUQUELIN, 2007, p. 97). Uma vez mais, reforça-se, pela imagem, o papel relevante da visão na experiência do mundo em geral, e das paisagens, em particular. Também, pontue-se a marcante influência da literatura sobre os sítios turísticos, vigente nos séculos XVIII e XIX e que hoje foi praticamente suplantada pela fascinação com as formas visuais da mídia, como televisão, cinema e fotografia (JENKINS, 2003).

Neste trabalho, num primeiro momento, objetiva-se reapresentar o caráter central da visibilidade, contida na percepção e no estudo das paisagens em geral, e das turísticas, em particular. Secundariamente, objetiva-se contrapor distintos paradigmas, quais sejam, do olhar e da performance, de modo a demonstrar a relativa migração do primeiro para o segundo, nos estudos da paisagem no/pelo Turismo.

Para atender aos objetivos de pesquisa, recorre-se a uma ampla revisão da literatura atinente à Geografia Cultural e Fenomenológica, ao Turismo e, em menor medida, à Sociologia, especialmente estrangeira, a fim de oferecermos uma visão do estado de conhecimento, que potencialmente sintetize conhecimento referente a essas questões, a fim de (re)introduzi-las. A literatura consultada é principalmente de língua inglesa e, em menor medida, espanhola.

\section{O PARADIGMA DO OLHAR NO TURISMO/LAZER}

Conforme problematiza Wylie (2007), o conceito de paisagem tem sofrido, ao longo de seu processo epistemológico - mesmo se considerarmos somente as últimas décadas sucessivas alterações e influências, oriundas da Filosofia e de outras Ciências Sociais. Devido a isso, o conceito de paisagem apresenta eminentes tensões entre os representantes das distintas correntes de pensamento geográfico. Na Geografia, o interesse 
pelas experiências de mundo do ser humano requer interrogar-se sobre os sentidos. As impressões que todo ser humano recebe do exterior, por meio desses sentidos, seriam “incomensuráveis", no dizer de Claval (2014). Um desses sentidos, a ser estudado, é o da visão.

Tuan (2012, p. 22) é enfático ao falar do ser humano na condição de animal visual: "Dos cinco sentidos tradicionais, o homem [sic] depende mais conscientemente da visão do que dos demais sentidos para progredir no mundo". O sentido da visão evoluiu em ambiente arbóreo, o que é, contudo, relativizado pela cultura e pela passagem do tempo histórico.

O órgão do sentido mais exercitado varia de acordo com o indivíduo e com sua cultura. Na sociedade moderna, o homem tem que confiar mais e mais na visão. Para ele, o espaço é limitado e estático, um quadro, uma matriz para os objetos. Sem objetos e sem fronteiras, o espaço é vazio (TUAN, 2012, p. 28).

A primazia da visão, já aludida, tem mais argumentos a seu favor quando atentamos para os diversos vocábulos - em língua inglesa, com alguns correspondentes em português - implicados com o olhar e a visão, tais como sight, vision, staring, seeing, gazing, entre outros. Os vocábulos significam, respectivamente, vista, visão, encarar, ver e olhar fixo (contemplação). Cosgrove (2002, p. 50, tradução nossa) enfatiza "[...] como tais diferentes palavras sugerem - envolve muito mais que uma resposta sensorial: a marca passiva e neutra das imagens formadas pela luz na retina do olho".

A visão é uma "primeira forma de organização simbólica"; contando com um logos implícito, certo pensamento visual e uma "inteligência perceptiva" (COLLOT, 2012, p. 17-18). Tais mecanismos e processos são estudados e descritos pela Psicofisiologia. A operação de perceber o longínquo, por exemplo, seria um ato de pensamento dos mais sofisticados, sem o qual não se tem uma paisagem (COLLOT, 2012).

Sanchez-Vasquez (1999), por sua vez, complementa que a visão, juntamente com a audição, seriam os sentidos propriamente estéticos, ao passo que Chaui (1999) é a filósofa a destacar a primazia da visão para a cognição humana. Tais características são relevantes para compreender a paisagem no fenômeno turístico.

Concorda-se com Berque (2009, p. 39, tradução nossa) quando assinala que "[...] a visão humana não é só uma questão de ótica; é também em grande medida questão de construção social. Com efeito, no mundo ao qual se pertence, se vê só o que convém ver, e o que não pertence a esse mundo [...] não se vê." No que tange à percepção e distinção das cores, Hall (2016) evidencia o quanto isso passa por filtros sensoriais, sobretudo de representações conceituais e culturais implícitas. Assim sendo, o sentido da visão humana é individualmente social, intencional e culturalmente condicionado (COSGROVE, 2002). 
De modo não dissonante, o conceito de gazing ressalta que olhar é uma habilidade a ser aprendida, e que um olho puro e inocente é um mito. Ver é o que o olho humano faz - já o gazing se refere a determinações discursivas do olhar socialmente construído. O olhar contemplativo sobre locais ou sítios (acrescenta-se, paisagens) é determinado por regras e estilos, bem como por representações que fazem tais vistas ou atrações circularem. Essas matrizes permitem aos turistas ver as formas físicas e espaços materiais ante seus olhos como interessantes ou belos, o que não é propriedade da visão de cada indivíduo (LARSEN; URRY, 2011).

Além disso, lembra Gomes (2013, p. 32) que "O ato físico do olhar é pouco criterioso e se nutre de um homogêneo e generalizado interesse. O olhar percorre e não se fixa". Por consequência: "Olhar pode ser amplo e geral, mas a visibilidade é sempre dirigida e parcial [...] A visibilidade é irremediavelmente não totalizadora [...] [mas] pode ser analisada minuciosamente em relação às razões que nos levam a ver e a não ver". Ainda, "a visibilidade é construída pela distribuição desigual do interesse por aquilo que é olhado [...] [em oposição] ao seu inverso, o invisível" (GOMES, 2013, p. 34). O autor, pois, delineia diferenças entre o olhar (amplo) e a visibilidade (seletiva). Similarmente, em termos de turismo, MacCannell (2001) defende que os paradigmas que estudam ou enquadram o olhar do turista devem deixar de conceber que ver é acreditar, pois algumas coisas ficarão escondidas, inclusive objetos familiares.

Escolhe-se, assim, a posição do olhar e, a partir desse posicionamento, serão determinados o ângulo, a direção e a distância, entre outros atributos da paisagem, que são posicionais. Desse modo, é a posição, espécie de trama locacional no/do espaço, que torna um objeto, sob o ponto de vista geográfico, algo visível. As posições exercem papel relevante nessa visibilidade, não sendo, porém, absolutas: elas são portadoras de sentidos e atributos (GOMES, 2013).

Concebe-se que a visibilidade da paisagem sempre será uma composição, "[...] um conjunto estruturado de formas, cores ou coisas" (GOMES, 2013, p. 23). Nesse sentido, a visibilidade é função da exposição, a qual é definida pela situação espacial, e, também, pela posição de exterioridade. "Lugares de exposição são lugares de grande e legítima visibilidade" (GOMES, 2013, p. 23). Em tal contexto de exposição encontram-se os destinos turísticos, as cidades globais e os centros cívicos, entre outros. A visibilidade, bem como a exposição, depende:

[...] das leituras do sentido que emergem da associação entre o lugar e do evento [...] dependerão também da possibilidade da morfologia do espaço físico onde se mostra e que deve ser capaz de garantir uma convergência dos olhares e a desejada captura da atenção [...] [por fim] esse lugar deve garantir a presença de observadores sensíveis aos novos sentidos da 
associação entre o lugar e o evento que se apresenta (GOMES, 2013, p. 36-37).

Nota-se, assim que: "O lugar físico e o enredo dentro dos quais um objeto [materialidade] é exibido são elementos estruturantes para sua compreensão" (GOMES, 2013, p. 30). Ou seja, parece haver (re)arranjos nos lugares de exposição e visibilidade a fim de promover determinados encontros, inclusive os turísticos.

Nessa geografia do olhar, despontam os diferentes regimes de visibilidade, que variam de acordo com o tempo, o espaço, a sociedade e/ou a cultura. Os regimes de visibilidade seriam "[...] uma espécie de protocolo, de cartilha de procedimentos regulares, que estabelecem socialmente aquilo que deve ser visto, as condições e os valores que devem ser julgados" (GOMES, 2013, p. 51-52). Tais regimes, modulados pela espacialidade, dotam de sentido as paisagens e sítios turísticos, e, também, "[...] nos informam sobre o que deve ser visto, como aquilo que é visto deve ser entendido e, simultaneamente, o que não merece ser visto" (GOMES, 2013, p. 52). Fornecem, ainda, condições necessárias para a interpretação do que está sendo exposto, ou seja, sua legitimidade. Eles são "regimes de verdade" em Michael Foucault, designando "[...] quem está autorizado a falar, o tipo de discurso que é aceito como verdadeiro [...]" (GOMES, 2013, p. 52).

Há um regime de visibilidade dito ordinário, porque "[...] previsível, repetitivo, não impactante", e outro, extraordinário o primeiro "[...] capta a atenção, cria ou se associa a um evento, tem impacto, mobiliza e interfere nessa ordem do cotidiano" (GOMES, 2013, p. 51). O chamado olhar turístico, especificamente, compreende discursos, práticas visuais aprendidas, signos, tecnologias visuais, lugares para ver, turistas portando câmeras, portanto, o visualmente extraordinário (LARSEN; URRY, 2011). MacCannel (2001) questiona, porém, se ao assumir essa posição, não se estaria presumindo que a vida ou o cotidiano de todos, é maçante, o que parece não ir ao encontro da realidade.

De todo modo, considere-se que o turismo é marcado, delimitado e consolidado, predominantemente, por um regime de visibilidade do extraordinário. O contrário também é válido, no sentido de que um sujeito, objeto ou evento, estando em uma diferente localização, pode ter seu regime de visibilidade alterado.

Mesmo concordando que a visão não é o único sentido envolvido na experiência turística, ela seria um sentido organizador: organiza o lugar, bem como o papel a ser desempenhado pelos sujeitos-turistas, além de afetar os outros sentidos (LARSEN; URRY, 2011). O adendo é o de que na percepção e na experiência as impressões oriundas de cada um dos sentidos não são dissociadas pelos sujeitos, mas adquirem contornos de um todo unificado. 
Apesar do que foi escrito em torno do sentido da visão e das condições de visibilidade, Cosgrove (2008) fala da desconfiança da Geografia em torno da visão e da imagem, a qual estaria enraizada na segunda onda feminista dos anos 1980 e 1990, em que o gaze seria inescapavelmente voyeurístico, dominador e explorador, que se demandava resistência: críticas semelhantes foram direcionadas, em paralelo, na área do Turismo (KNUDSEN; SOPER; METRO-ROLAND, 2007), nas obras iniciais de Urry (1996). Contudo, pontuemos que o próprio Urry fez evoluir sua teoria, do olhar fixo e unidirecional, para abarcar, num segundo momento, a globalização e as questões tecnológicas e de mobilidade - versão 2.0 do Olhar do Turista, dos anos 2000 -, até alcançar a incorporação mais clara das performances, movimentos e corporeidades na sua teoria do Turismo, em que o olhar é visto como relacional. Ele agregou até mesmo preocupações em torno da problemática do consumo de combustíveis fósseis na mobilidade (versão 3.0, anos 2010), segundo o que narra e discute Larsen (2014). Essas mudanças estiveram em consonância com a emergência e consolidação do novo paradigma das mobilidades nas Ciências Sociais.

Diante desses embates, teorias surgiram ainda na Geografia e no próprio Turismo, notadamente ligadas às práticas e à performance, como a teoria não representacional, ou, como prefere Lorimer (2005), mais-que-representacional.

\section{O PARADIGMA DA PERFORMANCE NO TURISMO/LAZER}

A visão e olhar estão, pois, afastados das práticas corporificadas (performing)? Como os estudos representacionais encaminham essa questão? $\mathrm{E}$ quanto aos não representacionais ou mais-que-representacionais? Potocka (2013), por exemplo, ao falar sobre paisagens turísticas lacustres, chama a atenção para como os valores visuais/estéticos da paisagem determinam atividades de lazer no ambiente natural, bem como certas atividades ou práticas de turismo. Assim, há crescente preocupação no que tange à necessidade de considerarem-se os distintos aspectos da experiência turística, não apenas os referentes ao olhar, mas a pautar tambéma corporeidade, a materialidade e a multissensorialidade (TERKENLI, 2007).

Para Bellentani (2016), a Semiótica, em sua versão tradicional, edificou uma barreira entre os conceitos de textos e o de práticas. Já em uma tendência pós-estrutural na/da Semiótica, o texto "paisagem" não estaria mais apartado das práticas que continuamente a conformam. Isso porque as práticas são "[...] sistemas coerentes de conhecimento experiencial que descrevem como atores habitualmente se comportam dentro de situações sociais"; por exemplo: o comportamento dos comensais em restaurantes "[...] dificilmente sofrem de mudanças abruptas ou são reescritas por circunstâncias não convencionais" (BELLENTANI, 2016, p. 81, tradução nossa). Isto quer dizer que algumas práticas humanas 
são estáveis, previsíveis ou estereotipadas. Como contraponto ao conceito tradicional de texto, as práticas são abordadas como abertas ou incertas, sujeitas à mudança de acordo com as configurações espaciais e temporais cambiantes.

Já segundo Cresswell (2002), "prática" é um conceito que recentemente teve impacto significativo sobre a Geografia Cultural. Suas origens e difusão estão na Teoria Crítica, nos Estudos da Performance, nas Teorias Feministas e na Teoria Social Pós-Marxista. As diferentes teorias têm uma origem comum no filósofo Merleau-Ponty, para quem a prática corpórea seria o modo mais básico de intencionalidade - categoria fundamental na Fenomenologia. Ainda segundo Cresswell (2002), no estudo da paisagem é problemático colocar o sentido da visão em estrita oposição à perspectiva do texto, na medida em que desse modo ficariam de fora as indeterminações e as improvisações presentes nas práticas.

Minca (2007, p. 439, tradução nossa) sugere "[...] repensar a hegemonia do visual, não apenas no seu papel central dentro da estruturação do pensamento moderno, mas também pelos quais a paisagem foi - e continua a ser concebida". As práticas implicam considerar o que é feito, não só o que é representado, permitindo assim que se redimensione o papel e o valor dos outros sentidos, como superação da supremacia da visão, pelo menos no que concerne a tê-la como único sentido a ser considerado.

De modo consonante, o paradigma do olhar turístico (gazing) é doravante abordado como relacional. Assim sendo, performances comunais envolvem negociações corporais e verbais, além de interações entre membros de uma equipe sobre o que ver, como vê-lo, e por quanto tempo. Miradas individuais são mediadas e afetadas, permitidas ou restringidas, pela presença do olhar dos outros turistas, que contribuem decisivamente para influenciar o olhar turístico (LARSEN; URRY, 2011).

A tese de Larsen e Urry (2011), então, é de que há similitudes entre os paradigmas do gazing e o da performance, ou seja, entre o olhar e o praticar/desempenhar. Deve-se atentar ao fato de que a virada performativa se volta mais ao estudo dos atos e fazeres do que propriamente para as representações e significações.

Destaca-se certa correspondência sócio-histórica entre a valoração das paisagens e a difusão de determinadas práticas turísticas. Por exemplo, somente entre o fim do século XVIII e princípios do XIX é que a montanha se tornou moda, como resultado da aparição de uma estética do grandioso, do sublime, e até mesmo do terrífico, coincidindo com o nascimento e difusão do alpinismo (NOGUÉ, 2008). Posição semelhante é assumida por Pimentel e Castrogiovanni (2015), quando colocam o desenvolvimento do olhar do turista, que também esteve atrelado com a curiosidade científica. Esses autores também reforçam que o montanhismo tem a ver com o código estético do Romantismo. "O espaço turístico seria, assim, a produção de um discurso e de uma imagem sobre os lugares que desperta o 
desejo de lhe experienciar turisticamente, de ali realizar determinadas práticas" (PIMENTEL; CASTROGIOVANNI, 2015, p. 446).

Paisagens e práticas parecem estar sendo (re)tecidas por meio do turismo/dos turistas. Jenkins (2003) pesquisou a representação da Austrália no mercado canadense, por meio da relação entre paisagens e práticas presentes em fotografias. A autora observou que o material publicitário voltado a mochileiros mostra muito mais as práticas, principalmente esportes ao ar livre, tais como ski-diving, bungee-jumping, mergulho e passeios a cavalo, por exemplo. Já o material voltado a um público convencional tem tendência a apresentar acomodações, instalações e, quando muito, atividades passivas como comer e beber. Contudo, a autora também observa alguns temas em comum entre os dois públicos, como algumas paisagens rochosas.

Por sua vez, Cresswell (2002) defende enfaticamente que as práticas não sejam obliteradas do estudo da paisagem na contemporaneidade. Para tal, é necessário ir além do dualismo ou da tensão dialética entre olhos e corpos. Desse modo, as "paisagens da prática" representam uma "[...] injeção de temporalidade e movimento" na paisagem "estática" (CRESSWELL, 2002, p. 280, tradução nossa). O autor reconhece, ainda, que a integração entre paisagem e prática é inerente a essa concepção de performances. Wylie (2007) questiona até mesmo se esse movimento não se caracteriza, em alguma medida, como sendo anti-paisagem, ou seja, se pode haver um esvaziamento do conceito na/pela Geografia, ou ainda, se a concepção das teorias não representacionais pode estar sendo levada a um extremo.

A perspectiva das performances turísticas propriamente ditas surge a partir de insights dos Estudos Culturais e das Teorias da Performance, como a de Erving Goffman (interacionismo). Parte-se do princípio de que as identidades determinam performances, definindo, por sua vez, os sítios/lugares tais como eles são - incluindo os turísticos. Há, nesse sentido, um habitus (termo emprestado de Pierre Bourdieu) turístico. Questiona-se se esse habitus turístico não poderia estar vinculado a determinados regimes de visibilidade, conforme abordados por Gomes (2013).

Embora comumente concebidos a partir de noções de fuga da normatividade, os turistas, vistos pelas performances, podem carregar consigo hábitos e respostas cotidianas, que formam parte da sua bagagem. O turismo pode ser também concebido como um conjunto de atividades imbricadas com o cotidiano, mediante o qual determinadas convenções podem ser reforçadas ou rompidas. Até mesmo os segmentos de turismo que se propõem a rejeitar turistas convencionais, ou não exclusivos, acabam imbuídos com suas próprias convenções (EDENSOR, 2001).

A série de recomendações dos guias de turismo ou nos guias de viagem, por exemplo, implica que os turistas devem agir ou performar de modos específicos. Se determinados 
cursos de ação, pré-determinados, não forem levados a cabo durante a viagem, uma suspeita é invocada de que o turista não aproveitou adequadamente a viagem ou o destino, ou até mesmo de que performance turística será deficiente, ou incompetente. Ainda, parece haver certa vigilância entre/de/para turistas, de modo a assegurar a realização da performance conforme o roteiro pré-concebido socialmente.

Os espectadores e participantes do "espetáculo" acabam agindo a partir de um olhar disciplinar cujo alvo são os sujeitos que performam. Assim sendo, a pertinência de uma performance recai sobre a habilidade de um grupo de compartilhar significados que os atores intentam transmitir. Parece haver uma vigilância, que é interna e externa, que pode acabar por restringir as performances, além de contribuir para assinalar convenções sobre os modos (in)apropriados de ser(-estar) turista (EDENSOR, 2001), ou tornar-se turista (SCARLES, 2009).

Além disso, observem-se as interações entre performers e espaço. A natureza do que podemos chamar de palco turístico contextualiza e baliza performance: a organização, materialidade e as qualidades sensoriais e estéticas do espaço turístico influenciam fortemente - mas não determinam totalmente - os tipos deperformances que os turistas empreendem (EDENSOR, 2001). Qual o papel da paisagem-cenário para o desempenho de determinadas práticas e performances?

Isto porque espaço turístico é cada vez mais preparado ou elaborado para tal retome-se a ideia dos encontros turísticos $(\mathrm{CROUCH}, 1999)$. Mais do que isso, o espaço turístico é também (re)produzido pelos turistas, os verdadeiros responsáveis por performar diversos significados dos sítios turísticos, demonstrando certa fidelidade a lugares e cursos de ação. É possível, assim, saber mais sobre as identidades individuais e de grupo (de turistas), aludindo a geografias imaginadas das quais o palco pode ser parte constitutiva (EDENSOR, 2001). Mais do que as próprias instalações ou o ambiente construído, é a performance fator da maior relevância para a existência de um sítio turístico: se a performance da mobilidade turística deixa de ocorrer, se o movimento cessa, os sítios turísticos cessam de sê-lo como tais (SHELLER; URRY, 2004). Diante do exposto, o turismo torna-se um processo a envolver contínua (re)construção da práxis e do espaço em contextos sempre compartilhados entre os sujeitos. Concebe-se, então, que determinados palcos (praias, montanhas ou cidades), permitem, de algum modo, que certas práticas ou performances ocorram. Contudo, mesmo que haja performances dominantes, pode ocorrer sobreposição de performances contestadoras, expressando diferentes disposições ou até mesmo identidades, de acordo com classe, gênero ou etnia, entre outros aspectos (EDENSOR, 2001). 
Edensor (2001), por fim, realiza uma análise não exaustiva dos tipos de performances que entram em jogo nos palcos do turismo, durante os encontros com a alteridade. $O$ primeiro grupo se refere às performances orientadas por identidades: "O turismo torna-se veículo para a transmissão de identidade, empreendendo uma forma particular de viagem, em um estilo específico". A leitura de guias de viagem alternativos ajuda a "[...] mediar a experiência deles de lugares e costumes não familiares" (EDENSOR, 2001, p. 73, tradução nossa). Como exemplo desse grupo, pode-se falar nos circuitos off-road, em geral.

Um segundo grupo é formado pelas performances não conformistas, buscando evitar a reiteração forçada das normas. Essas performances também oferecem um modo do qual se quer desviar, e uma oportunidade para marcar a subjetividade. Em paralelo, há performances cínicas. As performances improvisadas, por seu turno, partem do princípio que "A performance normatiza e suas instruções ofuscam a real contingência da performance e as inumeráveis possibilidades de performances disponíveis" (EDENSOR, 2001, p. 76, tradução nossa).

Edensor (2001) elenca, ainda, as performances involuntárias, em que nunca se pode prever com precisão como determinada performance será lida, de modo que é possível ressaltar uma natureza ambivalente do turismo, ou seja, pode tanto reforçar o dado culturalmente, quanto apresentar performances potencialmente subversivas. O autor também destaca performances pós-turísticas, como certa preocupação reflexiva da natureza construída de uma personagem, mas ao mesmo tempo uma vontade de desafiá-la. Entretanto, pós-turistas apresentam uma performance suavemente subversiva, revelando, contudo, algumas convenções turísticas.

A Figura 1 apresenta exemplos de performances turísticas estudadas a partir de fotografias de visitantes postadas publicamente no Instagram, ancoradas em paisagens da Lagoa Mirim (na fronteira entre Brasil e Uruguai), no veraneio 2019/2020 - para mais resultados verificar Kunz (2021). 
Figura 1 - Exemplos de performances presentes em fotografias.

Orientada por
identidade

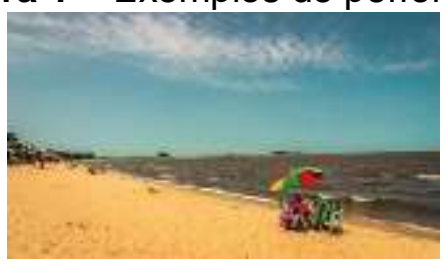

Pós-turística

Involuntária

Improvisada
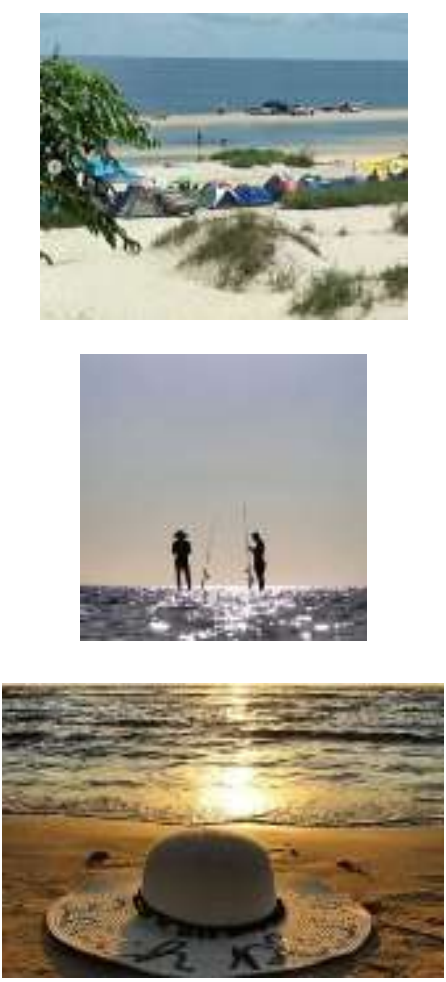

Não conformista

Cínica

Contestadora
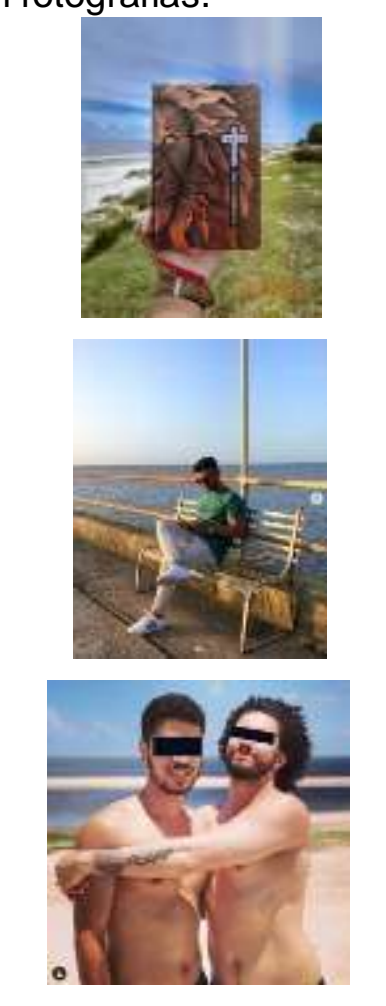

Contestadora

Fonte: adaptado de Kunz (2021).

\section{OLHAR E PERFORMANCE: A PAISAGEM TURÍSTICA COMO RECONCILIAÇÃO?}

Sobre rodas e com a propulsão a motor, aquele que se desloca (turista) não está mais na paisagem, mas a observa com relativo distanciamento. O espaço, abordado desse modo, será imagem, ou narrativa visual, em que deslocar-se, supõe, entre outros aspectos, adequação do olhar à velocidade (GASTAL, 2013). Assim, Crouch (2010, p. 214, tradução nossa) defende que "[...] a paisagem pode ser reconhecida como dinâmica e processual, através da consideração relacional das representações, com o caráter da vida e suas práticas, através de cada qual a paisagem indiscutivelmente acontece".

Apesar da tradicional dominância atribuída à visão, nota-se uma gradativa mudança teórica, inclusive na Neurologia, em direção a maior entendimento das relações entre esse sentido e outros sentidos humanos, tais como audição, tato e paladar. Tem-se reconhecido que o olho está sempre corporificado e incorporado a um corpo de "carne e osso". De fato, a classificação convencional em cinco sentidos - enquanto intuitivamente diga respeito a 
distintos órgãos localizados em diferentes partes do corpo - parece ser levada em direção a um esquecimento científico dos quatro elementos aristotélicos, conforme se reconhece que nenhum sentido opera independentemente dos outros; quando, em vez disso, o corpo é um todo muscular, esquelético, orgânico e neurológico (COSGROVE, 2008). Assim, como apontam Larsen e Urry (2011), é possível questionar: Até que ponto os dois paradigmas (gazing e performing) são de fato antagônicos, ou podem ser complementares no estudo do Turismo/Lazer e, em especial, de suas paisagens?

Diante do exposto, faz-se coro à Minca (2007) quando pergunta: O que a paisagem turística se torna quando ela é performada, ou quando é colocada em prática? Em decorrência de estudos realizados em praça central de Marrakech, no Marrocos, o autor questiona: Como os turistas realizam a performance do/no palco (ou cenário) da paisagem? Como eles negociam a relação entre as cartografias das narrativas turísticas oficiais e/ou institucionalizadas, e as suas próprias experiências materiais desse lugar como paisagem?

$\mathrm{Na}$ condição de turistas, participa-se de quadros como esses, da praça marroquina, sem sequer considerar as questões elencadas. Por vezes, justificam-se atitudes por meio de razões práticas: pode-se pensar no exemplo de ir tomar um café ou no de ir à praia. Porém, em realidade, pode-se estar fazendo parte de um verdadeiro espetáculo, sendo, a um só tempo, sujeito e objeto de uma performance, de uma encenação. A atuação dos sujeitos se soma a outras, produzindo efeitos por vezes inesperados ou indeterminados (GOMES, 2013). Assim como o espaço é representado como palimpsesto, também a paisagem é representada como estratigrafia de práticas e textos (CRESSWELL, 2002), recordando a divisão comum entre textos e práticas na Semiótica (BELLENTANI, 2016).

Por fim, cogita-se se as performances turísticas não podem ser o elo entre o olhar e as práticas, abordagens por vezes pouco consideradas. A tentativa é a de oferecer um modo de reconciliar, por meio da performance turística (mais-que-representacional), o texto "paisagem" e as práticas que Ihe são inerentes. A possibilidade dessa interação entre práticas e representações de paisagem turística é a fotografia, tanto no que tange ao encaminhamento teórico-conceitual da questão, quanto no que se refere às metodologias (visuais) que a adotam como ponto de partida.

\section{FOTOGRAFIA DA PAISAGEM TURÍSTICA: DE REGISTRO A PERFORMANCE}

As fotografias, cada vez mais instantâneas, fundem-se ao nosso cotidiano como nunca. A fotografia digital está em constante evolução, sob um complexo de redes, tecnologias, práticas e significados incorporados na vida cotidiana (LARSEN; SANDBYE, 2014). As (relativamente) novas práticas de fotografia digital são mais bem compreendidas como emergentes, na relação tanto com a mídia fotográfica em sua versão antiga, quanto 
com as tecnologias e potenciais de seus praticantes. Assim sendo, defende-se que as tais tecnologias não podem ser separadas dos fazeres e das práticas corporificadas.

Como a natureza da fotografia turística muda a partir da transição para a fotografia digital? Larsen (2014, p. 32, tradução nossa) observa que os turistas que posam para câmeras analógicas tendem a passar mais tempo compondo e coreografando cada foto: "Equipados com câmeras digitais [especialmente smartphones], os turistas tendem a fotografar mais rápido, gastando menos tempo em cada fotografia. Isso é porque cada fotografia é livre de custos, além de deletável". Tanto o álbum de fotos quanto a tela de uma câmera digital são tidos como objetos materiais que funcionam por meio da presença e das performances do falar e do mostrar (LARSEN, 2014). Assim, está-se diante de um relativamente novo regime de visibilidade das imagens, com cambiantes condições de exposição, em que observadores facilmente alternam-se com produtores, não havendo mais um ponto de vista privilegiado, como infere Gomes (2013). Expressão sempre relevante para entendermos a própria evolução do conceito de paisagem.

Contudo, as possibilidades específicas das tecnologias moldam os seus usos e sua compreensão na prática, embora não os determinem completamente. Há que se desestabilizar a ideia da fotografia como prática uniforme de significados culturais fixos; em vez disso, a fotografia é uma prática complexa e diversa, que atravessa o espaço-tempo. Seria ingênuo conceber que todos os fotógrafos conferem o mesmo significado às fotografias, tampouco que todos seguem as mesmas práticas. As fotografias têm que ser entendidas sempre em relação às sociedades nas quais estão inseridas; assim, devem ser abordadas simultaneamente como prática social, tecnologia em rede, objeto material e como imagem (LARSEN; SANDBYE, 2014).

"A fotografia sempre foi uma prática turística emblemática": o turismo e a fotografia são tidos como irmãos (LARSEN; SANDBYE, 2014, p. 25, tradução nossa), inseparáveis na Modernidade, com trajetórias aproximadas. Hoje em dia, porém, a materialidade e o destino das fotografias dos turistas são cada vez mais indeterminadas. Nesse contexto é que despontam as teorias não representacionais e mais-que-representacionais anteriormente aludidas. As imagens não são apenas representações, mas também "[...] blocos de sensação com intensidade afetiva" (LARSEN; SANDBYE, 2014, p. 27, tradução nossa). Objetos fotografados têm dimensão espacial e temporal: são objetos performativos, em que as sensações são corporalmente sentidas.

Diante disso, explicita-se: "O ato da fotografia é uma prática espacial - e a fotografia é um modo de experenciar um ambiente físico, um lugar ou local [além de paisagens]" (SHANKS; SVABO, 2014, p. 241). E, cada vez mais, a propensão para documentar em tempo real torna-se um aspecto da experiência turística ou mesmo do cotidiano. 
Crang (1999) declara que uma porção de sensações, expectativas, modelos préconcebidos, além de imagens não digeridas, explicam pelo menos em parte o anseio (ou a ânsia) por fotografar; esse nos invade quando estamos diante de uma paisagem especial, a ponto de ter a sensação de uma necessidade, quase instintiva, de fixá-la e congelá-la face a essa visão, em um momento e lugar ideais. Reitera-se que, em vez de ver fotografias como símbolos de significado oculto, pode-se pensar nas práticas envolvidas na sua produção e circulação, em que há uma autoria e uma narrativa.

Bell (2010) realizou escrutínio das diferentes práticas fotográficas dos turistas, por meio de imagens clicadas por sujeitos, seguidas de entrevista sobre a fotografia em si, bem como sobre o processo de tirá-la. Segundo a autora, essa metodologia permitiu descrever a significância do local e da paisagem pesquisadas (Muro de Adriano, Reino Unido), bem como suas experiências, experiências e (des)encontros, sendo que a técnica mais recorrente é utilizar a fotografia dentro das entrevistas de elicitação por imagens. Para esse estudo (BELL, 2010), câmeras descartáveis foram distribuídas, havendo limite no número de fotos clicadas, as quais não podiam ser alteradas. Se tivesse sido uma fotografia digital, provavelmente teria havido uma seleção daquelas melhores segundo cânones estéticos, não permitindo, na opinião dela, revelar suas experiências e encontros. A ideia foi categorizar e tematizar as fotos para tentar compreender o que os turistas experenciaram, de modo ativo, a fim de descobrir os modos de intencionalidade (turística) dos fotógrafos.

Os resultados encontrados variaram bastante. A fotografia é muito pessoal, mas requer uma narrativa verbal para conferir maior profundidade ao seu significado; ou seja, sem uma explicação, a fotografia estaria completamente aberta em termos de interpretação (BELL, 2010). A autora obteve desde fotos que os turistas normalmente tirariam, até fotos de infraestruturas, buscando observar a agenda do pesquisador, ou a partir de razões estéticas, embora a maioria seja uma combinação desses; variou se trabalhavam, moravam ou visitavam, bem como o tempo da visita. A tipologia das práticas fotográficas - mais propriamente das práticas e não exatamente dos sujeitos-turistas foi: compartilhamento de conhecimento (local); montagem de álbum de família; demonstração de um fotógrafo feliz; reprodução de imagem icônica; sightseer (apreciador-turista); elaboração de documentação; prática de arquivo; e composição fotográfica técnica; na resposta direta ao solicitado pelo pesquisador (BELL, 2010).

Destaque-se que uma das categorias fundamentais para se estudar a imagem fotográfica é o enquadramento, que leva em conta o ângulo de tomada. Por exemplo, o ângulo à altura do fotógrafo e de frente é aquele que confere maior impressão de realidade e/ou naturaliza uma cena, ao limitar a visão dita natural, e distinguem-se de outros ângulos mais sofisticados, como o oblíquo, acabando por ressaltar o operador da fotografia. Tudo isso parece ter a ver com a performance, a representação e os significados do sujeito na/da 
paisagem: diferentemente da câmera baixa muito leve, por exemplo, uma câmera alta discreta acaba conferindo "[...] ao espectador a impressão de dominar um pouco uma paisagem" (JOLY, 2012, p. 95). Assim, a característica reflexiva dos métodos visuais de pesquisa revela-se meio eficaz para que os sujeitos-participantes contemplem suas experiências, e assim construam narrativas sobre seus encontros com as paisagens e os sítios visitados. A técnica realizada por Bell (2010) evocou sentimentos por meio do engajamento com a imagem e da reflexão sobre a prática de fotografar.

A fotografia, ademais de ser um registro ou uma representação de uma paisagem, sempre culturalmente condicionada, é também expressão dos aspectos performáticos conforme elencados e propostos por Edensor (2001) - envoltos na relação corpóreo-visual entre sujeitos-turistas e o multissensorial das paisagens. Dado o exposto, preconiza-se que as metodologias visuais, as quais envolvem o uso da fotografia, podem ser um modo privilegiado de estudar paisagens turísticas nos seus aspectos visuais, mas também performáticos e narrar as práticas nos/dos sítios turísticos.

\section{CONSIDERAÇÕES FINAIS}

Neste texto, o intuito foi o de promover o cotejo entre distintos teóricos que, oriundos de áreas afins, apresentassem concepções e paradigmas distintos e complementares. Buscou-se propor uma união possível entre o que a Nova Geografia Cultural entende como modos de ver na/da paisagem, e o que a Geografia de cunho fenomenológico concebe como prática, ou seja, como geograficidade, como ser-estar-no-mundo, em que a corporeidade é característica essencial. Buscou-se revisitar obras estrangeiras que tratassem sobre gazing e performing. A essas obras se seguiu um intenso debate sobre a pertinência da ideia de gazing no âmbito dos estudos do Turismo, o que também se manifestou nas áreas da Geografia e da Sociologia. Não por acaso autores que trabalham os aspectos performáticos (da paisagem ou não) são os mesmos que atuam no novo paradigma das mobilidades, como Tim Cresswell, John Urry e Jonas Larsen. Há que se mobilizar o estudo das paisagens, turísticas ou não, e isso se dá por meio das abordagens das práticas e das performances. Essas, embora sejam oriundas de literaturas e autores distintos, possuem aproximação em termos dos propósitos de utilização.

Além disso, ointento foi reavaliar as bases teóricas e os paradigmas contemporâneos que assentam análises e sínteses a respeito de paisagens turísticas na literatura de língua inglesa, ainda não comumente referenciada por pesquisadores brasileiros, geógrafos ou turismólogos. Como limitações, não se consultou referencial em língua francesa, por 
exemplo. Entretanto, cabe referenciar que esforços de pesquisas empíricas de validação do referencial aqui discutido são relevantes.

Buscou-se reunir evidências na/da literatura em Geografia e Turismo que apontassem para a superação da divisão estrita entre olhar (representacional) e performar (nem sempre representacional) e, num segundo momento, perguntar-se sobre a pertinência da prática fotográfica ser um elo possível entre essas instâncias da paisagem, as quais, embora possam ser associadas, seguem distinguíveis. Assim, se a fotografia revela-se, por um lado, suporte para a compreensão das representações da paisagem pelos sujeitos-turistas, por outro, ela se manifesta como desafio metodológico, ao que se solicita a aplicação de técnicas e ferramentas compatíveis de utilização e análise de imagens, inovadoras e as mais completas possíveis, acionando-se conhecimentos da Antropologia Visual e da Imagem, bem como da Comunicação, o que não foi aqui realizado, por delimitação de escopo disciplinar e epistemológico. Outra limitação do trabalho foi não apontar, neste momento, desdobramentos para a operacionalização e organização do turismo como cadeia produtiva, enquanto assinala-se que o turismo se trata de um fenômeno sociocultural complexo, de que a atividade é consequência.

Ainda para futuros trabalhos, há que se estabelecer uma discussão mais ampla sobre os aspectos metodológicos envolvidos na produção e no uso de fotografias para compreensão da paisagem turística, além de que, este trabalho centrou-se nas práticas de produção de fotografias pelos turistas nos regimes de visibilidade e condições de exposição vigentes, e não nas de difusão e utilização dessas fotografias no círculo de representação no/do turismo.

\section{REFERÊNCIAS}

BELL, Victoria. Visual methodologies and photographic practices: Encounters with Hadrian's Wall World Heritage Site. In: BURNS, Peter; LESTER, Jo-Anne; BIBBINGS, Lyn (org.). Tourism and visual culture. Oxfordshire: Cabi Publishing, 2010. p. 120-132.

BELLENTANI, Federico. Landscape as text. In: HIGHERA, Claudio Rodríguez; BENNET, Tyler James (org.). Concepts for semiotics. Tartu: Tartu Press, 2016. p. 76-87.

BERQUE, Augustin. El pensamento paisajero. Madrid: Biblioteca Nueva, 2009.

CAUQUELIN, Anne. A invenção da paisagem. São Paulo: Martins Fontes, 2007.

CHAUI, Marilena. Janela da alma, espelho do mundo. In: NOVAES, Adauto (org.). O olhar. São Paulo: Companhia das Letras, 1999. p. 31-61.

CLAVAL, Paul. Epistemologia da Geografia. Florianópolis: UFSC, 2014.

COLLOT, Michel. Pontos de vista sobre a percepção de paisagens. In: NEGREIROS, Carmen; ALVES, Ida; LEMOS, Masé (org.). Literatura e paisagem em diálogo. Rio de Janeiro: Edições Makunaima, 2012. p. 11-28. 
COSGROVE, Denis. Geography and vision: seeing, imagining and representing the world. London: IB Auris, 2008.

COSGROVE, Denis. Landscape and the European Sense of Sight - Eyeing the Nature. In: ANDERSON, Kay; DOMOSH, Mona; PILE, Steve; THRIFT, Nigel (org.). Handbook of cultural geography. London: Sage, 2002. p. 249-268,

CRANG, Mike. Knowing, tourism and practices of vision. In: $\mathrm{CROUCH}$, David (org.). Leisure/tourism geographies: practices and geographical knowledge. London: Routledge, 1999. p. 239-256.

CRESSWELL, Tim. Landscape and the obliteration of practice. In: ANDERSON, Kay et al. (org.). Handbook of cultural geography. London: Sage, 2002. p. 259-282.

$\mathrm{CROUCH}$, David. Flirting with space: thinking landscape relationally. Cultural Geographies, London, v. 17, n. 1, p. 5-18, jan. 2010.

$\mathrm{CROUCH}$, David. Introduction: encounters in leisure/tourism. In: $\mathrm{CROUCH}$, David (org.). Leisure/tourism geographies: practices and geographical knowledge. London: Routledge, 1999. p. 1-16.

EDENSOR, Tim. Performing tourism, staging tourism: (re)producing tourist space and practice. Tourist Studies, London, v. 1, n. 1, p. 59-81, jun. 2001.

GASTAL, Susana de Araujo. Imagem, paisagem e turismo: a construção do olhar romântico. Pasos, El Sauzal, v. 11, n. 3, p. 123-133, 2013.

GOMES, Paulo César da Costa. O lugar do olhar: elementos para uma geografia da visibilidade. Rio de Janeiro: Bertrand Brasil, 2013.

HALL, Stuart. Cultura e representação. Rio de Janeiro: PUC-Rio, 2016.

JENKINS, Olivia. Photography and travel brochures: the circle of representation. Tourism Geographies, London, v. 5, n. 3, p. 305-328, 2003.

JOLY, Martine. Introdução à análise da imagem. Campinas: Papirus, 2012.

KNUDSEN, Daniel; RICKLY-BOYD, Jillian; METRO-ROLAND, Michelle. Landscape perspectives on tourism geographies. In: WILSON, Julie (org.). The routledge handbook of tourism geographies. London: Routledge, 2012. p. 201-207.

KNUDSEN, Daniel; SOPER, Anne; METRO-ROLAND, Michelle. Commentary: gazing, performing and reading: a landscape approach to understanding meaning in tourism theory. Tourism Geographies, London, v. 9, n. 3, p. 227-233, 2007.

KUNZ, Jaciel Gustavo. Paisagens e turismo na-da Lagoa Mirim (Brasil-Uruguai): complexus de práticas e significados. 2021. Tese (Doutorado em Geografia) - Universidade Federal do Rio Grande do Sul, Porto Alegre, 2021.

LARSEN, Jonas. The (Im)mobile life of digital photographs: the case of tourist photography. In: LARSEN, Jonas; SANDBYE, Mette (org.). Digital snaps: the new face of photography. London: I. B. Tauris, 2014. p. 25-46.

LARSEN, Jonas; SANDBYE, Mette. Introduction: the new face of snapshot photography. In: LARSEN, Jonas; SANDBYE, Mette (org.). Digital snaps: the new face of photography. London: I. B. Tauris, 2014. p. xv-xxiii.

LARSEN, Jonas; URRY, John. Gazing and performing. Environment and Planning D. Society and Space, London, v. 29, n. 6, p. 1110-1125, Jan. 2011.

LORIMER, Hayden. Cultural geography: the busyness of being more-than-representational. Progress in Human Geography, London, v. 29, n. 1, p. 83-94, 2005. 
MACCANNELL, Dean. The ethics of sightseeing. Berkeley: University of California Press, 2011.

MACCANNELL, Dean. Tourist agency. Tourist Studies, London, v. 1, n. 1, p. 23-37, June 2001.

MINCA, Claudio. El sujeto, el paisaje y el juego posmoderno. In: NOGUÉ, Joan Font (org.). El paisaje en la cultura contemporánea. Madrid: Biblioteca Nueva, 2008. p. 209-232.

MINCA, Claudio. The tourist landscape paradox. Social \& Cultural Geography, London, v. 8, n. 3, p. 433-453, Ago. 2007.

NOGUÉ, Joan Font. Introducción: la valorización cultural del paisaje en la contemporaneidad. In: NOGUÉ, Joan Font (org.). El paisaje en la cultura contemporánea. Madrid: Biblioteca Nueva, 2008. p. 9-24.

PANOFSKY, Erving. Significado nas artes visuais. São Paulo: Perspectiva, 2017.

PIMENTEL, Maurício Ragagnin; CASTROGIOVANNI, Antonio Carlos. Geografia e turismo: em busca de uma interação complexa. Rosa dos Ventos, Caxias do Sul, v. 7, n. 3, p. 440458, jul./set. 2015.

POTOCKA, Ilona. The lakescape in the eyes of a tourist. Quaestiones Geographicae, Poznan, v. 32, n. 3, p. 85-97, 2013.

SANCHEZ-VAZQUEZ, Adolfo. Convite à estética. Rio de Janeiro: Civilização Brasileira, 1999.

SCARLES, Caroline. Becoming tourist: renegotiating the visual in the tourist experience. Environment \& Planning D. Space and Society, London, v. 27, n. 3, p. 465-488, 2009.

SHANKS, Michael; SVABO, Connie. Mobile-media photography: new modes of engagement. In: LARSEN, Jonas; SANDBYE, Mette (org.). Digital snaps: the new face of photography. London: I. B. Tauris, 2014. p. 227-246.

SHELLER, Mimi; URRY, John. Places of play, places in play. In: SHELLER, Mimi; URRY, John (org.). Tourism mobilities: places to play, places in play. London: Routledge, 2004. p. 1-10.

SOUZA, Marcelo Lopes de Souza. Os conceitos fundamentais da pesquisa sócioespacial. Rio de Janeiro: Bertrand Brasil, 2016.

TERKENLI, Theano. Turismo e paisagem. In: LEW, Alan; HALL, C. Michael; WILLIAMS, Alan (org.). Compêndio de turismo. Lisboa: Instituto Piaget, 2007. p. 381-390.

TUAN, Yi-Fu. Topofilia: um estudo da percepção, atitudes e valores do meio ambiente. Londrina: Eduel, 2012.

URRY, John. O olhar do turista: lazer e viagens nas sociedades contemporâneas. São Paulo: Nobel, 1996.

WYLIE, John. Landscape. London: Routledge, 2007.

Recebido: fevereiro de 2021. Aceito: junho de 2021. 